\title{
MULTIPLE PERFORMANCE CHARACTERISTICS OPIIMIZATION OF HARD TURNING OPERATIONS USING UTIUTY BASED-TAGUCHI APPROACH
}

\author{
K Rahul Varma ${ }^{1 *}$ and M. Kaladhar ${ }^{2}$ \\ ${ }^{1}$ Department of Mechanical Engineering, Raghu Engineering College, Dakamarri,Visakhapatnam, \\ Andhra Pradesh, India-531162 \\ ${ }^{2}$ Department of Mechanical Engineering, DVR \& Dr. HS MIC College Of Technology, Kanchikacherla, \\ Vijayawada, Andhra Pradesh, India-521180 \\ *Corresponding author E-mail: rahul@raghueducational.com
}

\begin{abstract}
In order to sustain in the global competitive scenario, the manufacturing industries have been practicing the various tools to achieve the high quality products at lower cost. Selection of appropriate cutting conditions is necessary to improve machinabilty of a work piece material. The present work objective is to find out the optimum cutting parameters in turning of hardened AISI M2 steel using cryogenically treated cutting inserts. The Utility concept coupled with Taguchi approach was employed to optimize both surface roughness and power consumption simultaneously. According to Analysis of variance (ANOVA) results, the feed was the major dominant factor followed by the cutting speed on multiple performance characteristics. The necessary optimum conditions for multiple performance characteristics optimization were obtained as cutting speed of 100 $\mathrm{m} / \mathrm{min}$, feed $0.04 \mathrm{~mm} / \mathrm{rev}$ and depth of cut of $0.2 \mathrm{~mm}$.
\end{abstract}

Keywords: Hard turning, utility concept, Taguchi approach, surface roughness, power consumption, cryogenically treated cutting insert.

\section{INTRODUCTION}

Hardened materials whose hardness is more than 45 Rockwell hardness are widely used in engineering industries, machine tools, bearing steels, forging, high speed steels, automotive and aerospace industries. The products manufactured in these industries are sent for finishing at the final stage and it is carried out by grinding process. For the last few decades, grinding process is replaced by hard turning due to its certain disadvantages such as expensive machinery, low material removal rate, long cycle and set-up times. From the technological growth towards new cutting tool materials development; designing of rigid, stable and accurate machines emerges the concept of hard turning. It is a process of finish turning of hard materials whose HRC is in the 45-65 range. It is a viable alternative to grinding process and consists of potential advantages over grinding such as ecofriendliness, cost effectiveness, minimization of set-up times, better quality of manufactured products, inexpensive machinery and higher material removal rate $^{1,2}$. The $\mathrm{CBN}, \mathrm{PCBN}$, ceramic and coated carbide tools are extensively used for hard turning. Out of these, CBN and PCBN are preferable for hard machining ${ }^{3}$. The challenges involved in hard turning of materials has shifted from technological viability to economic viability due to, the complexity in processing these materials and high cost of CBN and PCBN inserts ${ }^{4}$. Therefore, in view of machining economics, many researchers have been striving to reduce tooling cost without compromising the quality characteristics. Many experimental studies have been conducted by using ceramic, advanced coated carbide and cryogenically treated cutting tools for finish hard turning with and without using cutting fluids ${ }^{5-14}$. Gill
SS et al. ${ }^{12}$ found that there was an enhancement in life of tungsten carbide tool by cryogenic action. Reddy TVS et al. ${ }^{13}$ observed that lower tool wear, cutting forces and surface roughness when turning with deep cryogenic treated P-40 tungsten carbide cutting tool inserts. Manu Dogra et al. ${ }^{14}$ evaluated the performance of CBN inserts during turning of AISI H11 steel and compared it with the other cutting inserts such as coated and uncoated inserts which were treated under cryogenic conditions. It was found that machining cost per cutting edge of the other inserts were lower when compared with CBN cutting inserts. As aforementioned, machining economics is not the only factor affecting tooling cost, but also includes other aspects such as reduction of production cost and time. In this regard, economic criteria seek selection of optimum machining parameters. In the manufacturing field, it is important to select the optimal cutting parameters. Selection of optimum cutting conditions yields maximum productivity and high quality with minimum cost and is traditionally relied on the operator's experience and industrial hand books which are not scientific methods. Taguchi's technique is widely used to obtain necessary number of experiments to determine the optimum level of cutting parameters. Some works have recently been carried out using planning and experimentation through the Taguchi's technique in optimization of process parameters ${ }^{15-19}$. Originally, Taguchi technique was able to optimize only one quality attribute by providing a best combination of machining parameters. However, the industrial products are evaluated by several quality aspects. As a consequence, a number of methods were developed for multiple performance characteristics optimization

Joumal of Mechanical Engineering, Vol. ME 45, No. 2, December 2015 Transaction of the Mec hanic al Engineering Division, The Institution of Engineers, Bangladesh 
in association with Taguchi method ${ }^{20}$. Hence, selection of cutting parameters is very essential for manufacturing industries, especially the rapidly growing industries like high speed steel (HSS) tool manufacturing industries. AISI M2 steel is a molybdenum series HSS steel. It has higher wear resistance, toughness and thermo plasticity when compared with tungsten series HSS steels. It is extensively used in manufacturing of drill bits, reamers, taps and dies. It is clear from the previous works that the no attention has been paid about the multiple performance characteristics optimization during hard turning of AISI M2 steel. Taguchi technique was used to conduct the experiments to hard turn AISIM2 molybdenum high speed steel on a lathe using deep cryogenically treated PVD coated cutting insert in the present investigation. The influence of cutting parameters on performance characteristics using ANOVA has been done. Furthermore, the work seeks to employ the application of the utility concept coupled with Taguchi technique for multiple performance roughness and power consumption by machine.

\section{METHODOLOGY}

Taguchi method is an exclusive and efficient robust design technique for experiments and improves the productivity to a great extent while minimizes the production cost. Taguchi suggested signal-to-noise $(\mathrm{S} / \mathrm{N})$ ratio to compare variations in responses through a quantitative value. Maximum value of $\mathrm{S} / \mathrm{N}$ ratio is desirable as it minimizes the response variation. According to Taguchi, the objective functions of various problems are divided into three types. Irrespective of the type of the objective function, the larger signal to noise ratio indicates improved performance. Hence the maximum value of signal to noise ratio gives the most favorable level of process parameter ${ }^{21}$. For judging the performance of a product/process by considering their relevant quality characteristics, a composite index is required to estimate its overall performance. Utility emphasizes a customer's satisfaction towards overall performance of a product. Utility concept establishes a utility function (U) which is a composite index of the individual utility functions ${ }^{22}$. Therefore, in the utility concept, the amalgamation of utilities of each specific quality attributes of a product indicates its overall utility. Further it optimizes the manufacturing process simultaneously. The utility function for overall performance of quality characteristics is given below:

$U\left(x_{1}, x_{2}, \ldots, x_{n}\right)=f\left[U_{1}\left(x_{1}\right), U_{2}\left(x_{2}\right), \ldots, U_{n}\left(x_{n}\right)\right]$ where $U\left(x_{1}, x_{2}, \ldots, x_{n}\right)$ is the overall utility of $\mathrm{n}$ is process performance characteristics and is $U_{i}\left(x_{i}\right)$ utility of $i$ th performance characteristics.

Estimated overall utility $=$

$U\left(x_{1}, x_{2}, \ldots, x_{n}\right)=\sum_{i=1}^{n} W_{i} U_{i}\left(x_{i}\right)$

(Assuming utility function is varying linearly)

Where, $\quad W_{i}=$ weight allocated to the $i$ th performance characteristic. In the present work, multiple performance characteristics, surface roughness $\left(R_{a}\right)$ and power consumption $(\mathrm{P})$ need to be minimized and thus 'smaller-the-better' type objective function was selected for each performance characteristic. The corresponding $\mathrm{S} / \mathrm{N}$ ratio as related with the performance characteristics $\mathrm{R}_{\mathrm{a}}, \mathrm{P}$ are set by,

$$
U_{1}=-10 \log _{10}\left[R_{a}^{2}\right] ; U_{2}=-10 \log _{10}\left[R_{q}^{2}\right]
$$

According to the Eq.1, the multiple- performance characteristics $\mathrm{S} / \mathrm{N}$ ratio for overall utility ${ }^{22}$,

$U=W_{1} U_{1}+W_{2} U_{2}$

In the present work, a weight allocated to the each performance characteristic is 0.5 which gives equal importance to all the performance characteristics for simultaneous minimization.

\section{EXPERIMENTAL PROCEDURE}

The cutting speed, feed and depth of cut with three levels of each were taken as the cutting conditions for the present work. On the basis of Taguchi technique $\mathrm{L}_{9}\left(3^{4}\right)$ orthogonal array was selected. The machining tests were carried out on a center lathe (Kirloskar make Turn Master 35). The chemical composition AISI M2 steel of diameter of $49.5 \mathrm{~mm}$ and $200 \mathrm{~mm}$ length is as follows: $\mathrm{C} \quad 0.89 ; \mathrm{Mn} \quad 0.26 ; \mathrm{Si} \quad 0.38 ; \mathrm{Cr}$ $3.95 ; \mathrm{Ni} \quad 0.31 ; \mathrm{Mo} \quad 4.78 ; \mathrm{W} \quad 6.05 ; \mathrm{V} \quad 1.75 ; \mathrm{Cu} \quad 0.16 ; \mathrm{P}$ $0.023 ; \mathrm{S} 0.0010$; Co 0.6.The work piece was heat treated to harden it. After the heat treatment, $60 \pm 2$ HRC was obtained. The PVD coated cutting tools were used which were given deep cryogenic treatment (Seco make, ISO code CNMG 120408). Mitutoyo SJ210 instrument was used for measuring surface roughness. To calculate power consumption at each experimental trial, cutting forces measurement was carried out by a Kistler three component Piezo electric dynamometer of type 9257B with a resonance of 3.5 $\mathrm{kHz}$. The dynamometer was positioned under the tool holder and coupled with a charge amplifier; type 5070 A. The schematic diagram of experimental set up is shown in Figure1.

Joumal of Mechanical Engineering, Vol. ME 45, No. 2, December 2015 


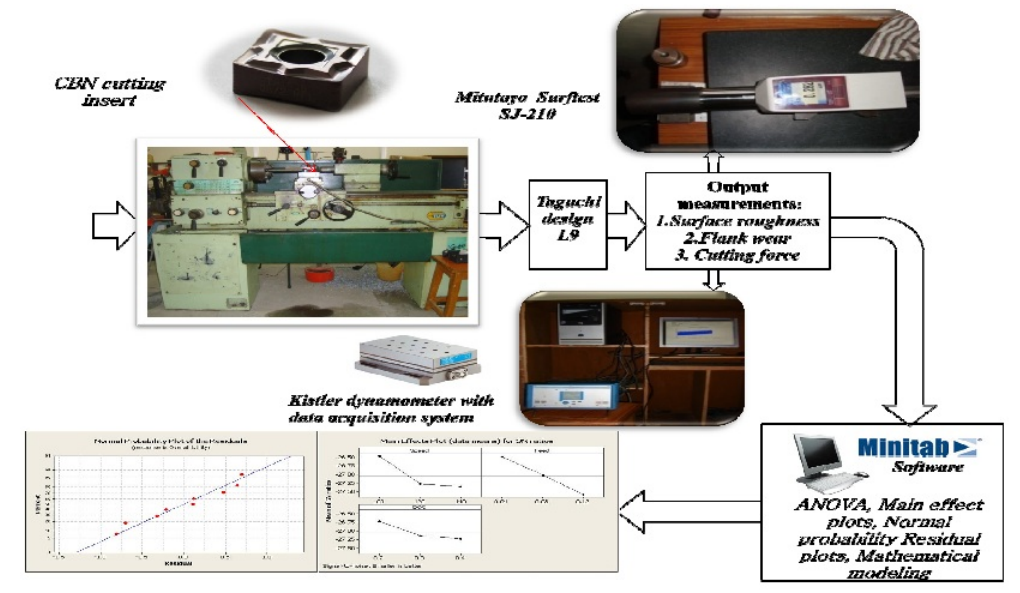

Figure 1. Experimental set-up.

\section{RESULTS AND ANALYSIS}

Table 1 shows the computational value of $\mathrm{S} / \mathrm{N}$ ratio for individual performance characteristic and multiple-performance characteristics by means of Eq.1 and 2. The variations of the experimental design can be measured by $\mathrm{S} / \mathrm{N}$ ratio. In order to attain high product quality, the desired outcome for manufacturing industries is the lowest possible surface roughness and power consumption. To achieve this, the smaller-the-better objective function was used for utility based Taguchi approach multiple performance characteristics in the present work. The Figure 2 shows multi-performance characteristics the average $\mathrm{S} / \mathrm{N}$ ratios of overall utility for each level of cutting parameters. Thus, from the Figure 2, the optimal process parameters for the present work are $\mathrm{A} 1, \mathrm{~B} 1, \mathrm{C} 1$ (highest $\mathrm{S} / \mathrm{N}$ ratios). The best combination of these values minimizes the surface roughness and power consumption simultaneously.

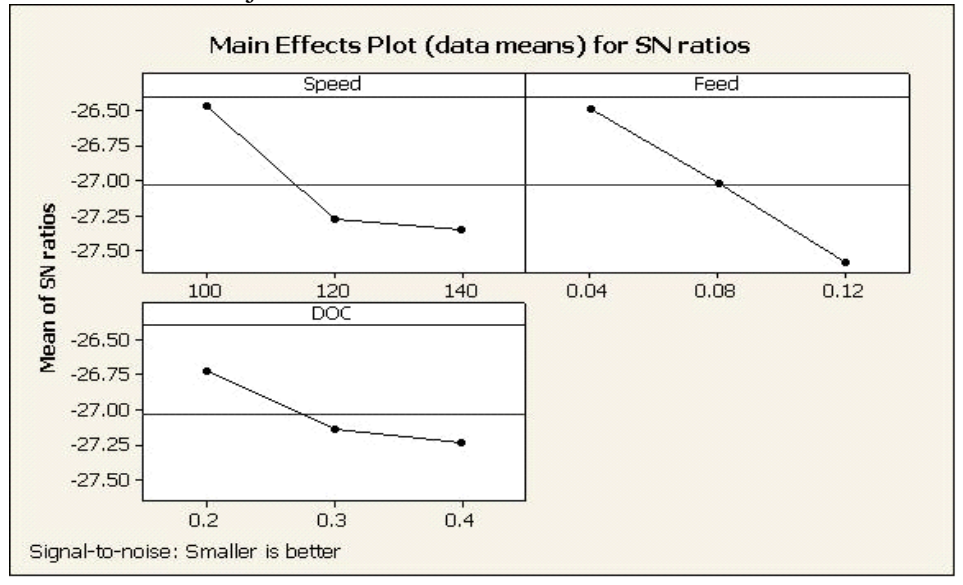

Figure 2. Effect of control factors on multiple $\mathrm{S} / \mathrm{N}$ ratio.

From the Figure 2 It has been found that, a low cutting speed of $100 \mathrm{~m} / \mathrm{min}$ was necessary for reducing surface roughness and power consumption. It can be verified empirically that very high temperature is generated at low cutting speed (as more contact between tool and work piece) during hard turning ${ }^{11}$. The high temperature causes thermal softening of the work piece and produces a smooth surface finish. The power consumption was also low at low cutting speed along with the combination of low depth of cut $0.2 \mathrm{~mm}$. The Figure 2 also shows the feed behavior against average $\mathrm{S} / \mathrm{N}$ ratios of overall utility. At low feed rate $0.04 \mathrm{~mm} / \mathrm{min}$, both the performance characteristics were minimized. The reason could be, the heat generation is more due to higher material removal at higher feed rates, it causes high flank wear and results more surface roughness. It is evident from the Figure 3 that higher cutting forces are recorded during turning at higher feed rates. As a consequence, power consumption is more at higher feed rates as the material removal rate is also higher. 

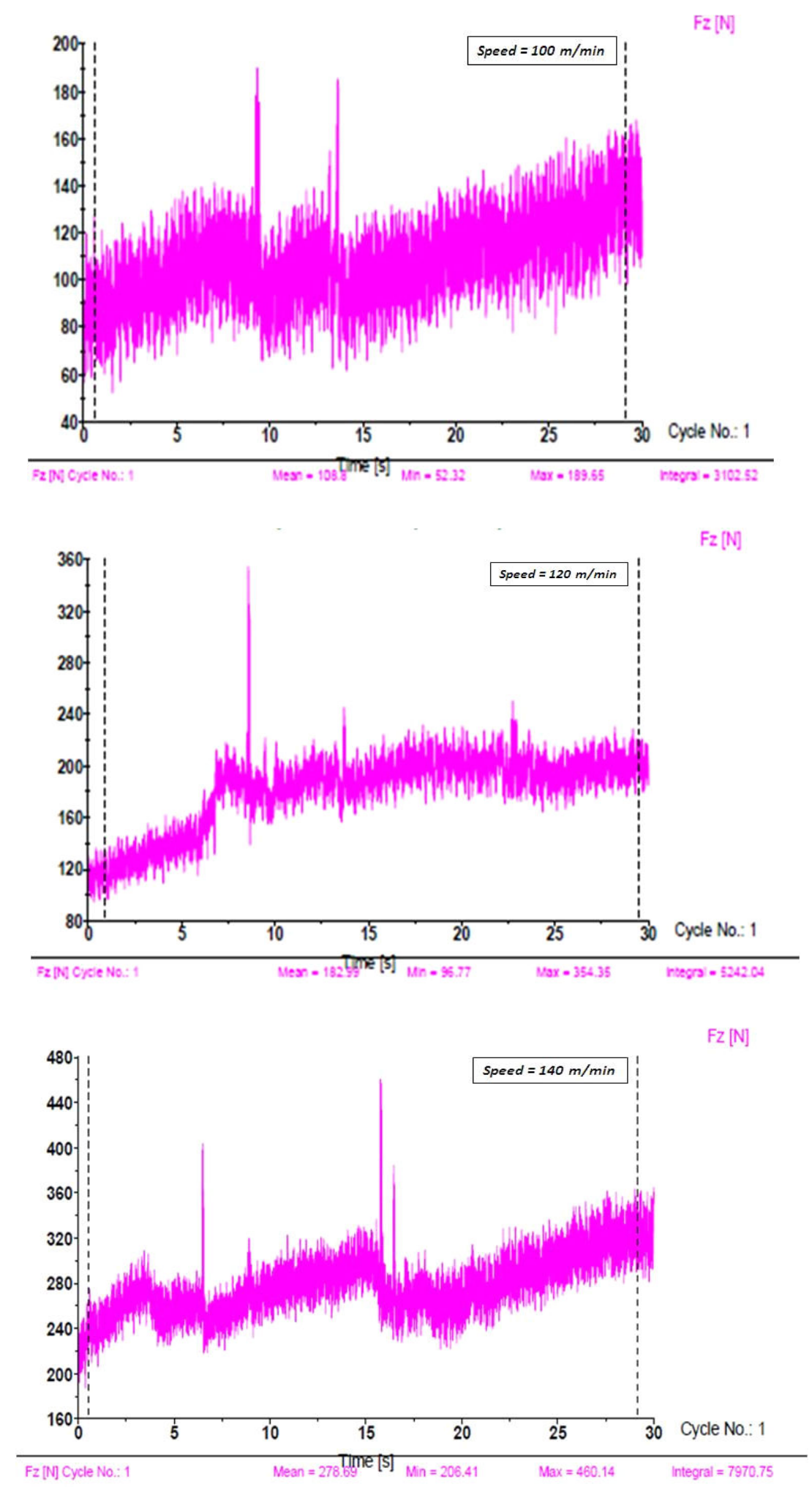

Figure 3. Cutting forces at a feed rate of $0.12 \mathrm{~mm} / \mathrm{rev}$ and varying speeds.

J oumal of Mechanical Engineering, Vol. ME 45, No. 2, December 2015

Transaction of the Mec hanic al Engineering Division, The Institution of Eng ineers, Bangladesh 
Table 1. Experimental results

\begin{tabular}{|c|c|c|c|c|c|c|c|c|}
\hline \multirow[b]{2}{*}{$\begin{array}{c}\text { Expt. } \\
\text { No }\end{array}$} & \multicolumn{3}{|c|}{ Levels of cutting parameters } & \multicolumn{2}{|c|}{$\begin{array}{l}\text { Performance } \\
\text { characteristics }\end{array}$} & \multicolumn{3}{|c|}{$\mathrm{S} / \mathrm{N}$ ratios } \\
\hline & $\begin{array}{c}\text { Cutting } \\
\text { speed } \\
(\mathrm{m} / \mathrm{min}) \\
\end{array}$ & $\underset{(\mathbf{m m} / \text { rev })}{\text { Feed }}$ & $\begin{array}{c}\text { Depth of } \\
\text { cut } \\
(\mathrm{mm})\end{array}$ & $\begin{array}{c}\mathbf{R}_{\mathbf{a}} \\
(\mu \mathrm{m})\end{array}$ & $\begin{array}{l}\text { Power } \\
\text { (W) }\end{array}$ & $\mathrm{U}_{1}(\mathrm{~dB})$ & $\mathrm{U}_{2}(\mathrm{~dB})$ & $\mathbf{U}(\mathbf{d B})$ \\
\hline 1 & 100 & 0.04 & 0.2 & 0.500 & 161.48 & 6.006141 & -44.1626 & -19.0782 \\
\hline 2 & 100 & 0.08 & 0.3 & 0.616 & 230.33 & 4.196648 & -47.2471 & -21.5252 \\
\hline 3 & 100 & 0.12 & 0.4 & 0.613 & 304.98 & 4.241345 & -49.6855 & -22.7221 \\
\hline 4 & 120 & 0.04 & 0.3 & 0.515 & 291.78 & 5.761039 & -49.3011 & -21.7700 \\
\hline 5 & 120 & 0.08 & 0.4 & 0.487 & 471.77 & 6.246443 & -53.4746 & -23.6141 \\
\hline 6 & 120 & 0.12 & 0.2 & 0.618 & 407.84 & 4.177884 & -52.2098 & -24.016 \\
\hline 7 & 140 & 0.04 & 0.4 & 0.479 & 383.30 & 6.378198 & -51.671 & -22.6464 \\
\hline 8 & 140 & 0.08 & 0.2 & 0.417 & 400.38 & 7.590345 & -52.0496 & -22.2296 \\
\hline 9 & 140 & 0.12 & 0.3 & 0.498 & 658.45 & 6.049607 & -56.3705 & -25.1605 \\
\hline
\end{tabular}

Once the optimal process parameters levels are selected, the final stage is the prediction and verification of both surface roughness and power consumption.

$$
U_{\text {pred }}=m+\sum_{j=1}^{p}\left[\left(m_{i j}\right)_{\max }-m\right]
$$

Where $\mathrm{m}=$ Overall mean of nine experimental trials $\mathrm{S} / \mathrm{N}$ ratios; $\left(m_{i j}\right)_{\max }=\mathrm{S} / \mathrm{N}$ ratio of optimum process parameters; $p=$ Number of significant factors

$$
\begin{aligned}
\eta_{\text {eff }}= & \frac{N}{1+\text { dofassociatedtothatlevel }} \\
& =\frac{9}{1+2+2+2}=1.285
\end{aligned}
$$

Where, $\mathrm{V}_{e}=0.12861$ (from ANOVA Table); $F_{(\alpha, 1, v e)}=F_{(0.05 \%, 1,3)}=10.128$ (from F-Table)

$$
\begin{gathered}
C I=\sqrt{F_{(\alpha, 1, v e)} * V_{e}\left(\frac{1}{\eta_{e f f}}+\frac{1}{\eta_{v e r}}\right)} \\
C I= \pm 1.5219 \mathrm{~dB}
\end{gathered}
$$

The prediction error $\left(U_{\text {pred }}-U\right)$ is $0.0892 \mathrm{~dB}$. It is observed that the error falls inside the CI value
According to the Eq. (3), the predicted value of $\mathrm{S} / \mathrm{N}$ ratio for $\mathrm{A} 1, \mathrm{~B} 1, \mathrm{C} 1$ parameter level combination is $18.989 \mathrm{~dB}$. After computing the predicted optimum value $\left(U_{\text {pred }}\right)$ and the experimental value $\left(U_{\text {expt }}\right)$ at the optimum levels in terms of $\mathrm{S} / \mathrm{N}$ ratio, the closeness of these two values must be checked by computing Confidence interval (CI) at $95 \%$ level. The CI for the predicted optimal value is calculated as follows ${ }^{21}$ :

i.e. $\pm 1.5217 \mathrm{~dB}$. Hence, the combination of optimum parameter level and additive model for the parameter effects in the present investigation is quite valid. Therefore the simultaneous optimization for surface roughness and power consumption of machine has been achieved using Utility based Taguchi approach at significant level of 0.05 .

The purpose of ANOVA is to find significant process parameters which influence the performance measures. ANOVA Table 2 illustrates that the feed rate $(50 \%)$ has shown major influence on multiperformance characteristics followed by cutting speed (38.84\%). However, depth of cut has shown least influence on multiple performance characteristics. And it is also found that there is negligible effect of interaction of cutting parameters on simultaneous minimization of surface roughness and power consumption by machine due to 0.001 percentage of error contribution. 
Table 2. ANOVA results for power (at $95 \%$ confidence level, $\mathrm{F}_{2,3} \equiv 9.552$ )

\begin{tabular}{cccccc}
\hline Source & DF & SS & Variance & F & C (\%) \\
\hline Speed & 2 & 9.15 & 4.57 & 35.533 & 38.837 \\
Feed & 2 & 11.80 & 5.90 & 45.875 & 50.084 \\
DOC & 2 & 2.61 & 1.30 & 10.108 & 11.078 \\
Error & 3 & 0.3858 & 0.12861 & & 0.001 \\
Total & 6 & 23.56 & & & \\
\hline
\end{tabular}

On the other side, the corresponding values of $\mathrm{F}$ for cutting parameters are greater than the F- table value. The optimal combination of process parameters and cryogenically treated cutting insert lead to predict a value which optimizes both surface roughness and power consumption

DEVELOPMENT OF MATHEMATICAL MODEL

A mathematical model establishes the correlation between machining responses and the process parameters to enable the optimization of machining process. In the present work, a multiple regression model was developed for overall utility. simultaneously that falls within the Confidence interval at high confidence percentage. Hence, the optimization results are accurate and flexible. The method employed in the present study can be applied in the tool manufacturing industries to improve the efficiency.

Table 3. Adequacy checking

\begin{tabular}{lccccc}
\hline Source & DF & SS & Variance & F & P $<\mathbf{0 . 0 5}$ \\
\hline Regression & 3 & 21.058 & 7.169 & 14.71 & 0.006 \\
Residual Error & 5 & 2.437 & 0.487 & \\
Total & 8 & 23.945 & & \\
\hline
\end{tabular}

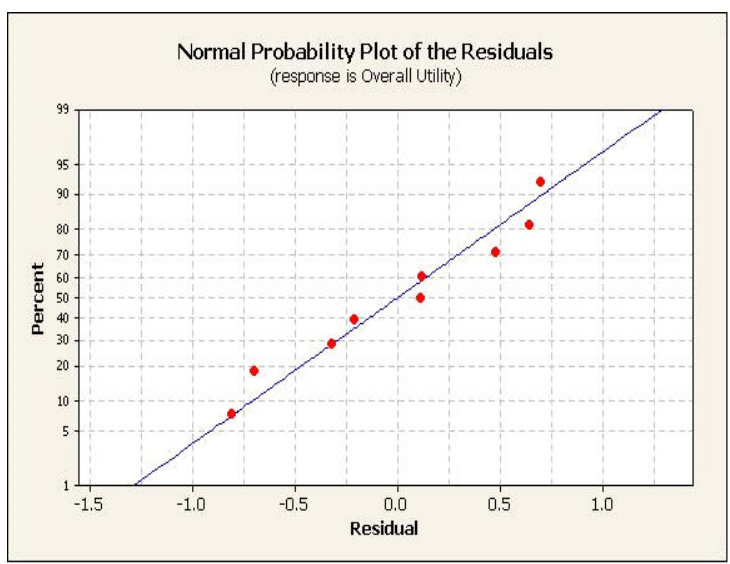

Figure 4. Normal probability plot of Residuals.

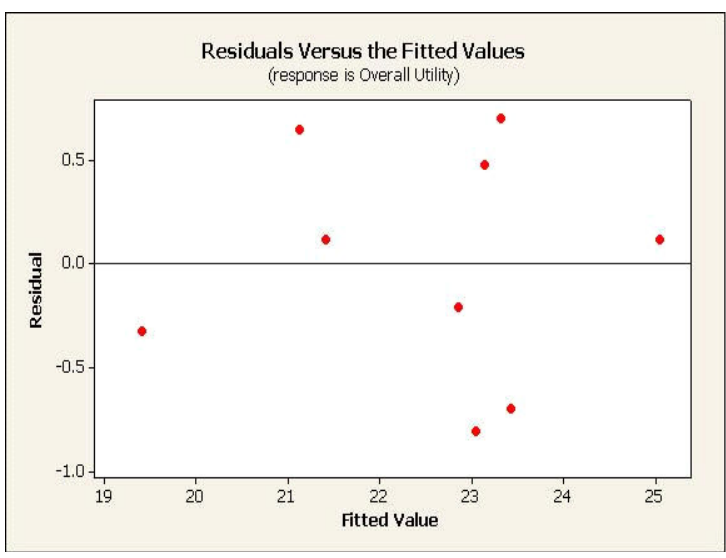

Figure 5. Residual plot for Residuals Vs Fitted values.

Joumal of Mechanical Engineering, Vol. ME 45, No. 2, Dece mber 2015

Transaction of the Mec ha nic al Engineering Division, The Institution of Engineers, Bangladesh 
The adequacy of a multiple regression model can be checked by ANOVA and coefficient of correlation $\mathrm{R}^{2}$. Employing ANOVA, the calculated $F$ value must be larger than the $\mathrm{F}$ table value and $\mathrm{P}$ value also must be less than $5 \%$ significant level. These conditions were satisfied in the developed model (Table 3). Another measure that is commonly used to test the adequacy of a fitted multiple regression model is the coefficient of correlation $\mathrm{R}^{2}$. The calculated $\mathrm{R}^{2}$ and adjusted $\mathrm{R}^{2}$ values for the developed model were $89.8 \%$ and $83.7 \%$ respectively. These values indicate that the developed model was adequate for prediction. The validity of regression model is tested by residual plots i.e. normal probability plot of the residuals and the plot of residuals versus fitted values. These plots are presented in Figures 4 and 5. The normal probability plot assess if the data is approximately normally distributed. The residuals should form an approximate straight line. The Figure 4 revealed that most of residuals are formed as a straight line. It indicates an almost perfect fit for the developed model of overall utility for multiple performance characteristics. In order to obtain a correct model and to satisfy the assumptions, the residuals should not show any definite structure. The Figure 5 showed that the there is no obvious pattern in residuals. This shows that the proposed model is good for prediction.

\section{CONCLUSIONS}

Hard turning is an eco-friendly, viable alternative for grinding process both performance and economic wise. The present work has substantially improved the quality of performance characteristics during hard turning of AISI M2 steel by use of cryogenically treated PVD coated cutting inserts. The cylindrical grinding process is generally used in tool manufacturing industry for finishing purpose. Generally, the expected range of surface roughness values for manufacturing industries is $0.063-5 \mu \mathrm{m}$. The obtained surface roughness values were fallen below the $0.618 \mu \mathrm{m}$ in the present work. On the other hand, the hybrid optimization method has been yielded the predicted optimal value for multipleresponse optimization, which has fallen inside the CI at high confidence percentage and was accurate and can be successfully applied for tool manufacturing industry. Some other conclusion can also be extracted from the work:

(i) The combination of optimal levels of cutting speed $100 \mathrm{~m} / \mathrm{min}$, depth of cut $0.2 \mathrm{~mm}$, feed rate 0.02 $\mathrm{mm} / \mathrm{rev}$ is necessarily required to minimize both surface roughness and power consumption simultaneously.

(ii) As per ANOVA outcome, feed rate and cutting speed are significant factors in optimizing both surface roughness and power consumption.

(iii) Feed rate is the more dominant one by contributing $50.08 \%$. The negligible error contribution
$(0.001 \%)$ is observed and specifies the nonexistence of cutting conditions interaction in multiple responses optimization.

(iv) It is also found that the developed model is quite satisfactory for finding out the optimum performance characteristics at 5\% significant level.

\section{REFERENCES}

1. Aneiro Federico, M., Coelho Reginaldo, T., Brandao Lincoln, C., 2008, " Turning hardened steel using coated carbide at high cutting speeds", J Brazil Soc Mech Sci Eng, Vol. 30, No. 2, pp.104-109.

2. Arockiajaswin, M., Mohanlal, D., 2010," Optimization of the Cryogenic treatment Process for En 52 valve steel using the Grey-Taguchi Method", Mater Manuf Process, Vol.25, No. 8, pp.842-850.

3. Chromg-Jytzeng ., Yung-Kuang Yang., 2008, “ Determination of Optimal Parameters for SKD11 CNC Turning Process", Mater Manuf Process, Vol. 23, No. 4, pp. 363-368.

4. Davim, J.P., Figueira, L., 2007," Comparative evaluation of conventional and wiper ceramic tools on cutting forces, surface roughness, and tool wear in hard turning AISI D2 steel", J Eng Manuf , Vol. 221, No.4, pp.625-633.

5. Domnita Fratila., Cristian Caizar., 2012, “ Investigation of the Influence of Process parameters and Cooling Method on the Surface Quality of AISI1045 during Turning", Mater Manuf Process, Vol. 27, No.10, 1123-1128.

6. Dureja, J.S, Gupta, V.K., Sharma, V.S., Dogra , M., 2010, "Wear mechanisms of TiN-coated CBN tool during finish hard turning of hot tool die steel", Proc I MechE Part B: J Eng Manuf , Vol. 224, No.1, pp. 553-566.

7. Gill, S.S., Singh, R., Singh, H ., Singh, J., 2009," Wear behaviour of cryogenically treated tungsten carbide inserts under dry and wet turning conditions', Int J Mach Tools Manuf, Vol. 49, No.3, pp. 256-260.

8. Jeyapaul, R., Shahabudeen, P., Krishnaiah, K., 2005, " Quality management research by considering multi-response problems in the Taguchi method-a review", Int J Adv Manuf Technol, Vol. 26, No.11, pp.1331-1337.

9. Kumar, P., Barua, P.B, Gaindhar, J.L., 2000, "Quality optimization (multi-characteristic) through Taguchi's technique and utility concept", Qual Reliab Eng Inter, Vol. 16, No. 1, pp.475-485.

10. Lahiff, C., Gordon, S., Phelan, P., 2007, “ PCBN tool wear modes and mechanisms in finish hard turning", Robot Comput Integr Manuf , Vol. 23, No.6, pp.638-644.

11. Manu Dogra., Vishal, S., Sharma., Anish Sachdeva., Narinder Mohan Suri., Jasminder, S., Dureja., 2011, " Performance evaluation of CBN, coated carbide, cryogenically treated uncoated/coated carbide inserts in finish-turning of hardened steel.", Int J Adv Manuf Technol, Vol. 57, No.5, pp. 541553.

Joumal of Mechanical Engineering, Vol. ME 45, No. 2, December 2015 Transaction of the Mec hanic al Engineering Division, The Institution of Engineers, Bangladesh 
12. More, A.S, Wenping, J., Brown, W.D., Malsh, A.P., 2006, " Tool wear and machining performance of cBN-TiN coated carbide inserts and PCBN compact inserts in turning AISI 4340 hardened steel", J Mater Process Technol, Vol. 180, N0. 13, pp. 253262.

13. Noordin, M.Y., Kurniawan, D., Sharif, S., 2007, "Hard turning of stainless steel using wiper coated carbide tool", Int J Prec Technol, Vol. 1, No. 1, pp. $75-84$.

14. Reddy, T.V.S., Sornakumar, T., Reddy, M.V., Venkatram, R., Senthilkumar, A., 2009, “ Turning studies of deep cryogenic treated P-40 tungsten carbide cutting tool inserts-technical communication", Mach Sci Technol, Vol. 13, No.2, pp.269-281.

15. Ross, P.J, 1996, "Taguchi Techniques for Quality Engineering", $2^{\text {nd }}$ Ed., McGraw-Hill., New York,pp.

16. Sales, W.F., Costa, L.A., Santos, S.C., Diniz, A.E., Bonney, J., Ezugwu, E.O., 2009," Performance of coated, cemented carbide, mixed ceramic and PCBN-H tools when turning W320 steel", Int J Adv Manuf Technol , Vol. 41, No.7, pp. 660-669.
17. Senthil Kumar, D., Rajendram, I., 2012, "Optimization of Deep Cryogenic Treatment to reduce wear loss of 4149 steel', Mater Manuf Process, Vol. 27, No. 5, pp.567-572.

18. Singh Dilbag., Rao, P.V., 2008, “ Performance improvement of hard turning with solid lubricants", Int J Adv Manuf Technol, Vol. 38, No. 5, pp.529535.

19. Sharma, V.S., Dogra, M., Suri, N.M., 2009, "Cooling techniques for improved productivity in turning", Int J Mach Tools Manuf, Vol. 49, No.6, pp. 435-453.

20. Suresh, R., Basavarajappa, S., Gaitonde, V.N., 2012, " Machinability investigations on hardened AISI 4340 steel using coated carbide insert", Int J Refract Met H, Vol. 33, No. 1, pp. 75-86.

21. Suresh, R., Basavarajappa, S., Samuel, G.L., 2012, "Some studies on hard turning of AISI 4340 steel using multilayer coated carbide tool", Measurement, Vol. 45, No. 7, pp.1872-1884.

22. Zhao-Peng Hao., Yong Lu., Dong Gao., Yi-Hang Fan., Yan-Li Chang., 2012, " Cutting parameters Optimization Based on Optimal Cutting Temperature in Machining Inconel 718", Mater Manuf Process, Vol. 27, No. 10, pp.1084-1089.

Joumal of Mechanical Engineering, Vol. ME 45, No. 2, Dece mber 2015 